\title{
Optimal doses of sevoflurane and propofol in rabbits
}

Yoshihide Terada', Tadahiko Ishiyama², Nobumasa Asano', Masakazu Kotoda², Kodai Ikemoto', Noriyuki Shintani ${ }^{1}$, Daniel I Sessler ${ }^{3}$ and Takashi Matsukawa ${ }^{1}$

\begin{abstract}
Background: Although sevoflurane and propofol are commonly used anesthetics in rabbits, optimal doses of remain unclear. We thus assessed the optimal hypnotic doses of sevoflurane and propofol, and evaluated the influence of dexmedetomidine on sevoflurane and propofol requirements.

Methods: Twenty-eight Japanese white rabbits were randomly assigned to one of four groups ( $n=7$ each). Rabbits were given either sevoflurane, propofol, sevoflurane + dexmedetomidine, or propofol + dexmedetomidine (injected $30 \mu \mathrm{g} \cdot \mathrm{kg}^{-1} \cdot \mathrm{hr}^{-1}$ for $10 \mathrm{~min}$ followed by an infusion of $3.5 \mu \mathrm{g} \cdot \mathrm{kg}^{-1} \cdot \mathrm{hr}^{-1}$ ). Hypnotic level was evaluated with Bispectral Index (BIS), a well-validated electroenchalographic measure, with values between 40 and 60 representing optimal hypnosis. BIS measurements were made 10 minutes after the adjustment of target end-tidal sevoflurane concentration in the sevoflurane group and sevoflurane + dexmedetomidine group, and at 10 min after the change of infusion rate in the propofol group and propofol + dexmedetomidine group.

Results: BIS values were linearly related to sevoflurane concentration and propofol infusion rate, with or without dexmedetomidine. Sevoflurane concentration at BIS $=50$ was $3.9 \pm 0.2 \%$ in the sevoflurane group and $2.6 \pm 0.3 \%$ in the sevoflurane + dexmedetomidine group. The propofol infusion rate to make BIS $=50$ was $102 \pm 5 \mathrm{mg} \cdot \mathrm{kg}^{-1} \cdot \mathrm{hr}^{-1}$ in the propofol group, and $90 \pm 10 \mathrm{mg} \cdot \mathrm{kg}^{-1} \cdot \mathrm{hr}^{-1}$ in the propofol + dexmedetomidine group.

Conclusions: The optimal end-tidal concentration of sevoflurane alone was thus 3.9\%, and optimal infusion rate for propofol alone was $102 \mathrm{mg} \cdot \mathrm{kg}^{-1} \cdot \mathrm{hr}^{-1}$. Dexmedetomidine reduced sevoflurane requirement by $33 \%$ and propofol requirement by $11 \%$.
\end{abstract}

Keywords: Bispectral index, Propofol, Sevoflurane, Rabbits, Anesthesia

\section{Background}

Anesthesia is required for many animal experiments, and often provided by sevoflurane or propofol. Those agents are also used in anesthesia for rabbits [1]. Nevertheless, optimal anesthetic doses of sevoflurane and propofol in rabbits remain unclear. Dexmedetomidine, a central alpha-2 receptor agonist, is sedative and also has hypotensive, analgesic, and anesthetic sparing properties [2]. The extent to which dexmedetomidine reduces the need for sevoflurane and propofol in rabbits remains unknown.

\footnotetext{
* Correspondence: ishiyama@yamanashi.ac.jp

${ }^{2}$ Surgical Center, University of Yamanashi Hospital, University of Yamanashi, 1110 Shimokato, Chuo, Yamanashi 409-3898, Japan

Full list of author information is available at the end of the article
}

The best-established monitor of hypnotic (anesthetic) depth is the Bispectral Index (BIS) which is based on human electroencephalogram, but has also been used in animals $[3,4]$. In this study we sought to clarify the BIS monitoring usefulness in establishing the optimal doses of sevoflurane or propofol in rabbits and also its usefulness in evaluating the influence of dexmedetomidine on sevoflurane and propofol anesthetic requirements in rabbits. Therefore, our primary goal was to determine the relationship between BIS and sevoflurane concentration or propofol dose in rabbits. Our secondary goal was to determine the optimal hypnotic doses of sevoflurane and propofol, and the extent to which dexmedetomidine reduced anesthetic requirement.

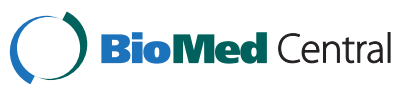

(c) 2014 Terada et al.; licensee BioMed Central Ltd. This is an Open Access article distributed under the terms of the Creative Commons Attribution License (http://creativecommons.org/licenses/by/4.0), which permits unrestricted use, distribution, and reproduction in any medium, provided the original work is properly credited. The Creative Commons Public Domain Dedication waiver (http://creativecommons.org/publicdomain/zero/1.0/) applies to the data made available in this article, unless otherwise stated. 


\section{Methods}

Experiments were performed on 28 healthy Japanese white rabbits weighing 2.8-3.9 kg. The Committee on Animal Research, University of Yamanashi, Yamanashi, Japan, approved this study. The acclimation period of the rabbits was more than 3 weeks. The rabbits were randomly assigned to one of four groups (sevoflurane, propofol, sevoflurane and dexmedetomidine, and propofol and dexmedetomidine; $\mathrm{n}=7$ in each group) based on anesthetic methods. After obtaining intravenous access in an ear vein, each rabbit was given either sevoflurane $5 \%$ in oxygen via mask or propofol $10 \mathrm{mg} \cdot \mathrm{kg}^{-1}$ iv followed by an infusion of $50 \mathrm{mg} \cdot \mathrm{kg}^{-1} \cdot \mathrm{hr}^{-1}$. Rocuronium $5 \mathrm{mg} \cdot \mathrm{kg}^{-1}$ was injected simultaneously. Rocuronium was injected intermittently as needed. Then the animals were tracheostomized under local anesthesia with $1 \%$ lidocaine and their lungs were mechanically ventilated with an oxygen-air mixture. End-tidal $\mathrm{CO}_{2}$ was continuously monitored (Vamos, Dräger medical, Tokyo, Japan), and the tidal volume and respiratory rate were adjusted to maintain arterial carbon dioxide tension between 35 and $45 \mathrm{mmHg}$. A femoral artery catheter was inserted to monitor arterial blood pressure. Bicarbonated Ringer's solution was infused at $10 \mathrm{~mL} \cdot \mathrm{kg}^{-1} \cdot \mathrm{h}^{-1}$. After completion of tracheotomy, sevoflurane was decreased to $1 \%$ in the sevoflurane anesthetized groups, and dexmedetomidine was injected $30 \mu \mathrm{g} \cdot \mathrm{kg}^{-1} \cdot \mathrm{hr}^{-1}$ for $10 \mathrm{~min}\left(5 \mu \mathrm{g} \cdot \mathrm{kg}^{-1}\right)$ followed by an infusion of $3.5 \mu \mathrm{g} \cdot \mathrm{kg}^{-1} \cdot \mathrm{hr}^{-1}$ in the sevoflurane and dexmedetomidine group. In the propofol group, infusion rate of propofol was continued at $50 \mathrm{mg} \cdot \mathrm{kg}^{-1} \cdot \mathrm{hr}^{-1}$. In the propofol and dexmedetomidine group, infusion rate of propofol was decreased to $25 \mathrm{mg} \cdot \mathrm{kg}^{-1} \cdot \mathrm{hr}^{-1}$ and dexmedetomidine was injected $30 \mu \mathrm{g} \cdot \mathrm{kg}^{-1} \cdot \mathrm{hr}^{-1}$ for $10 \mathrm{~min}\left(5 \mu \mathrm{g} \cdot \mathrm{kg}^{-1}\right)$ followed by an infusion of $3.5 \mu \mathrm{g} \cdot \mathrm{kg}^{-1} \cdot \mathrm{hr}^{-1}$. Rectal (core) temperature was maintained at $39 \pm 0.5^{\circ} \mathrm{C}$ by a heating blanket. Arterial blood pressure, heart rate and rectal temperature were recorded using Dynascope DS-7101 L (Fukuda Denshi, Tokyo, Japan).

The animals' heads were shaved, and a four-electrode pediatric BIS sensor was applied according to the previous method [3,5]. One electrode was placed $1 \mathrm{~cm}$ caudal to the eye socket and others were placed on the head. All electrode impedance levels were kept below $7.5 \mathrm{k} \Omega$. BIS values were obtained from an A-2000 monitor (Version XP-3.12, Aspect Medical Systems, Norwood, MA, USA). The BIS smoothing rate was set at 15 seconds. BIS is a unitless value that ranges from 0 to 100 , with values between 40 and 60 indicating a suitable hypnotic depth for surgery in humans [6].

After surgical procedures, 40 minutes were allowed for stabilization. Then measurements of BIS and other parameters such as arterial blood pressure, heart rate and rectal temperature were started. In the sevoflurane group, the inhaled concentration was progressively increased by $0.2 \%$ at 10 -minute intervals. In propofol and propofol + dexmedetomidine groups, the propofol infusion rate was progressively increased by $5 \mathrm{mg} \cdot \mathrm{kg}^{-1} \cdot \mathrm{hr}^{-1}$ at 10-minute intervals. In the sevoflurane + dexmedetomidine group, sevoflurane was initially inhaled at $1.0 \%$ and was sequentially increased by $0.5 \%$. BIS and other parameters such as arterial blood pressure, heart rate and rectal temperature were recorded 10 minutes after each dose adjustment. At the end of the experiment, each animal was killed by $\mathrm{KCl}$ infusion.

Systolic blood pressures, heart rates, and core temperatures were expressed as means \pm standard deviations. Those data were analyzed using analysis of variance followed by a post hoc Tukey's test. The BIS data was assessed using logistic regression, and mean and 95\% confidence intervals $(\mathrm{CI})$ were presented. Correlations between each measurement were examined using a scatter graph and linear regression. A $P$ value less than 0.05 was considered statistically significant.

\section{Results}

In the sevoflurane group, systolic blood pressure progressively decreased as a function of sevoflurane concentration (Table 1). In the sevoflurane + dexmedetomidine group, systolic blood pressure and heart rate were significantly lower than in the sevoflurane group (Table 1 ). Blood pressure and heart rate were similarly decreased in the propofol + dexmedetomidine group compared with those in the propofol group (Table 2).

BIS values correlated with end-tidal sevoflurane concentrations in the sevoflurane group (BIS $=83.8-8.7$. [sevoflurane (\%)], $\mathrm{r}=-0.677$; Figure 1 ) and the sevoflurane + dexmedetomidine group (BIS $=67.2-6.6$. [sevoflurane (\%)], $r=-0.662$; Figure 2). The BIS value was also highly correlated with propofol infusion rates in the propofol group $\left(\right.$ BIS $=95.2-0.44 \cdot\left[\right.$ Propofol $\left(\mathrm{mg} \cdot \mathrm{kg}^{-1} \cdot \mathrm{hr}^{-1}\right)$, $\mathrm{r}=-0.676$; Figure 3) and the propofol + dexmedetomidine group $\left(\right.$ BIS $=79.1-0.32 \cdot\left[\right.$ Propofol $\left.\left(\mathrm{mg} \cdot \mathrm{kg}^{-1} \cdot \mathrm{hr}^{-1}\right)\right]$, $\mathrm{r}=-0.558$; Figure 4).

The sevoflurane concentration required to produce a BIS value of 50 was $3.9 \pm 0.2 \%$ (95\% CI, 3.7-4.1\%) in the sevoflurane group (Figure 1) and $2.6 \pm 0.3 \%$ (95\% CI, 2.3-2.9\%) in the sevoflurane + dexmedetomidine group (Figure 2). The propofol infusion rate required to produce a BIS value of 50 was $102 \pm 5 \mathrm{mg} \cdot \mathrm{kg}^{-1} \cdot \mathrm{hr}^{-1}$ (95\% CI, 97$107 \mathrm{mg} \cdot \mathrm{kg}^{-1} \cdot \mathrm{hr}^{-1}$ ) in the propofol group (Figure 3) and $90 \pm 10 \mathrm{mg} \cdot \mathrm{kg}^{-1} \cdot \mathrm{hr}^{-1}$ (95\% CI, 80-100 $\left.\mathrm{mg} \cdot \mathrm{kg}^{-1} \cdot \mathrm{hr}^{-1}\right)$ in the propofol + dexmedetomidine group (Figure 4).

\section{Discussion}

Perhaps unsurprisingly, various species require different anesthetic concentrations. However, the potency of volatile anesthetics differs only slightly across species, with 
Table 1 Systolic blood pressure, heart rate and body temperature in the sevoflurane and sevoflurane + dexmedetomidine groups

\begin{tabular}{|c|c|c|c|}
\hline & Sevoflurane & Sevoflurane + dexmedetomidine & $P$ \\
\hline $\mathrm{SBP}(\mathrm{mmHg}) \mathrm{S} 1 \%$ & $131 \pm 24$ & $93 \pm 15$ & 0.0036 \\
\hline SBP $(m m H g) S 2 \%$ & $112 \pm 14$ & $86 \pm 16$ & 0.0068 \\
\hline SBP $(m m H g) S 3 \%$ & $107 \pm 19$ & $84 \pm 21$ & 0.0343 \\
\hline SBP $(m m H g) S 4 \%$ & $107 \pm 14$ & $92 \pm 16$ & NS \\
\hline SBP $(m m H g) S 5 \%$ & $101 \pm 7^{*}$ & $79 \pm 12$ & 0.0015 \\
\hline HR (bpm) S 1\% & $252 \pm 43$ & $222 \pm 62$ & NS \\
\hline HR (bpm) S 2\% & $258 \pm 71$ & $204 \pm 36$ & 0.0385 \\
\hline HR (bpm) S 3\% & $254 \pm 59$ & $227 \pm 25$ & NS \\
\hline HR (bpm) S 4\% & $239 \pm 38$ & $250 \pm 32$ & NS \\
\hline HR (bpm) S 5\% & $219 \pm 5$ & $267 \pm 37$ & 0.0058 \\
\hline BT $\left({ }^{\circ} \mathrm{C}\right) \mathrm{S} 1 \%$ & $38.6 \pm 0.8$ & $38.5 \pm 0.3$ & NS \\
\hline BT $\left({ }^{\circ} \mathrm{C}\right) \mathrm{S} 2 \%$ & $38.8 \pm 1.0$ & $38.6 \pm 0.3$ & NS \\
\hline BT $\left({ }^{\circ} \mathrm{C}\right) \mathrm{S} 3 \%$ & $38.9 \pm 1.2$ & $38.7 \pm 0.4$ & NS \\
\hline BT $\left({ }^{\circ} \mathrm{C}\right) \mathrm{S} 4 \%$ & $38.8 \pm 0.1$ & $39.0 \pm 0.4$ & NS \\
\hline $\mathrm{BT}\left({ }^{\circ} \mathrm{C}\right) \mathrm{S} 5 \%$ & $38.6 \pm 0.4$ & $38.5 \pm 0.5$ & NS \\
\hline
\end{tabular}

$\mathrm{SBP}=$ systolic blood pressure, $\mathrm{HR}=$ heart rate, bpm = beats per minutes, $\mathrm{BT}=$ body temperature, $\mathrm{S}=$ sevoflurane concentration, $\mathrm{NS}$ not significant, $* P<0.05$ versus $\mathrm{S} 1 \%$.

similar concentrations being required for insects, amphibian, rodents, and humans [7-9]. In contrast, requirements for intravenous anesthetics vary considerably. For example, many laboratory animals such as rodents require opioid and ketamine doses an order-of-magnitude greater than human patients $[10,11]$.
The classical measure of volatile anesthetic potency is the Minimum Alveolar Concentration (MAC) which is the partial pressure (or gas percentage) in the blood which prevents $50 \%$ of subjects from moving in response to a super-maximal painful stimulus such as a skin incision. End-tidal concentrations represent alveolar concentration

Table 2 Systolic blood pressure, heart rate and body temperature in the propofol and propofol + dexmedetomidine groups

\begin{tabular}{|c|c|c|c|}
\hline & Propofol & Propopol + Dexmedetomidine & $P$ \\
\hline $\mathrm{SBP}(\mathrm{mmHg})$ P 50 & $121 \pm 14$ & $107 \pm 20$ & NS \\
\hline $\mathrm{SBP}(\mathrm{mmHg}) \mathrm{P} 60$ & $112 \pm 13$ & $105 \pm 15$ & NS \\
\hline $\mathrm{SBP}(\mathrm{mmHg}) \mathrm{P} 70$ & $125 \pm 11$ & $108 \pm 27$ & 0.0473 \\
\hline $\mathrm{SBP}(\mathrm{mmHg}) \mathrm{P} 80$ & $123 \pm 8$ & $111 \pm 13$ & NS \\
\hline $\mathrm{SBP}(\mathrm{mmHg}) \mathrm{P} 90$ & $116 \pm 7$ & $102 \pm 17$ & 0.0344 \\
\hline $\mathrm{SBP}(\mathrm{mmHg}) \mathrm{P} 100$ & $117 \pm 9$ & $95 \pm 13$ & $<0.0001$ \\
\hline HR (bpm) P 50 & $264 \pm 29$ & $215 \pm 39$ & 0.0064 \\
\hline HR (bpm) P 60 & $242 \pm 34$ & $192 \pm 41$ & 0.0019 \\
\hline $\mathrm{HR}(\mathrm{bpm}) \mathrm{P} 70$ & $273 \pm 19$ & $208 \pm 32$ & $<0.0001$ \\
\hline HR (bpm) P 80 & $279 \pm 24$ & $206 \pm 20$ & 0.0001 \\
\hline HR (bpm) P 90 & $280 \pm 21$ & $221 \pm 18$ & $<0.0001$ \\
\hline HR (bpm) P 100 & $267 \pm 21$ & $218 \pm 23$ & $<0.0001$ \\
\hline BT $\left({ }^{\circ} \mathrm{C}\right)$ P 50 & $39.1 \pm 0.4$ & $39.2 \pm 0.6$ & NS \\
\hline $\mathrm{BT}\left({ }^{\circ} \mathrm{C}\right) \mathrm{P} 60$ & $39.0 \pm 0.5$ & $39.1 \pm 0.6$ & NS \\
\hline $\mathrm{BT}\left({ }^{\circ} \mathrm{C}\right)$ P 70 & $38.9 \pm 0.5$ & $39.2 \pm 0.6$ & NS \\
\hline $\mathrm{BT}\left({ }^{\circ} \mathrm{C}\right) \mathrm{P} 80$ & $39.2 \pm 0.4$ & $39.3 \pm 0.4$ & NS \\
\hline $\mathrm{BT}\left({ }^{\circ} \mathrm{C}\right) \mathrm{P} 90$ & $39.1 \pm 0.3$ & $39.2 \pm 0.6$ & NS \\
\hline $\mathrm{BT}\left({ }^{\circ} \mathrm{C}\right) \mathrm{P} 100$ & $38.6 \pm 0.6$ & $39.3 \pm 0.7$ & NS \\
\hline
\end{tabular}

$\mathrm{SBP}=$ systolic blood pressure, $\mathrm{HR}=$ heart rate, $\mathrm{bpm}=$ beats per minutes, $\mathrm{BT}=$ body temperature, $\mathrm{P}=$ propofol, $50,60,70,80,90,100=50,60,70,80,90,100 \mathrm{mg}^{\mathrm{k}} \mathrm{kg}^{-1} \cdot \mathrm{hr}^{-1}, \mathrm{NS}$ not significant. 


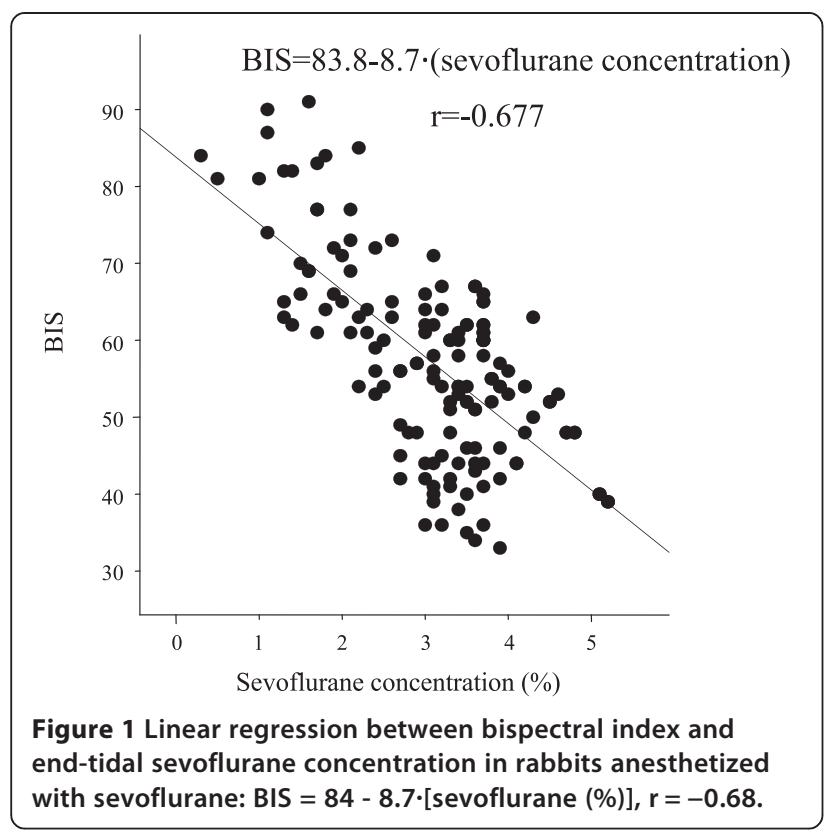

which is in equilibrium with blood and thus brain; endtidal concentrations thus represent effect-site concentrations. MAC is used to compare the potency of various volatile anesthetics, as well as to evaluate the effects of ancillary drugs [12], mutations [13], and ethnicity [14]. Although MAC is not defined for intravenous anesthetics, it is possible to determine the plasma concentration that prevents movement in $50 \%$ of human subjects [15].

While MAC is the oldest and best-established single measure of volatile anesthetic effect, it is hardly the only one. In fact, "anesthesia" is not a unitary function; in addition to lack of movement, it incorporates amnesia,

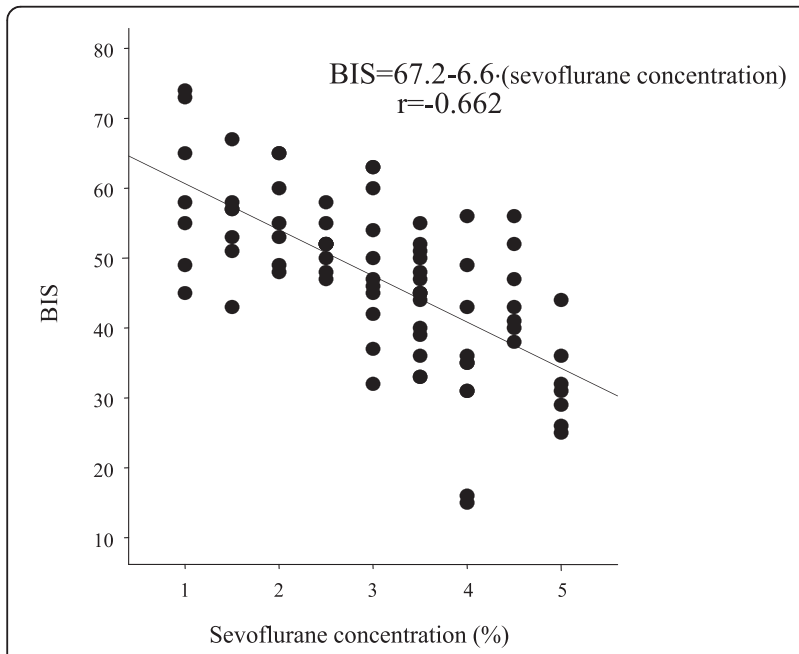

Figure 2 Linear regression between bispectral index and end-tidal sevoflurane concentration in rabbits anesthetized with sevoflurane and dexmedetomidine. Line represents linear correlation: $\mathrm{BIS}=67.2-6.6 \cdot[$ sevoflurane $(\%)], r=-0.662$.

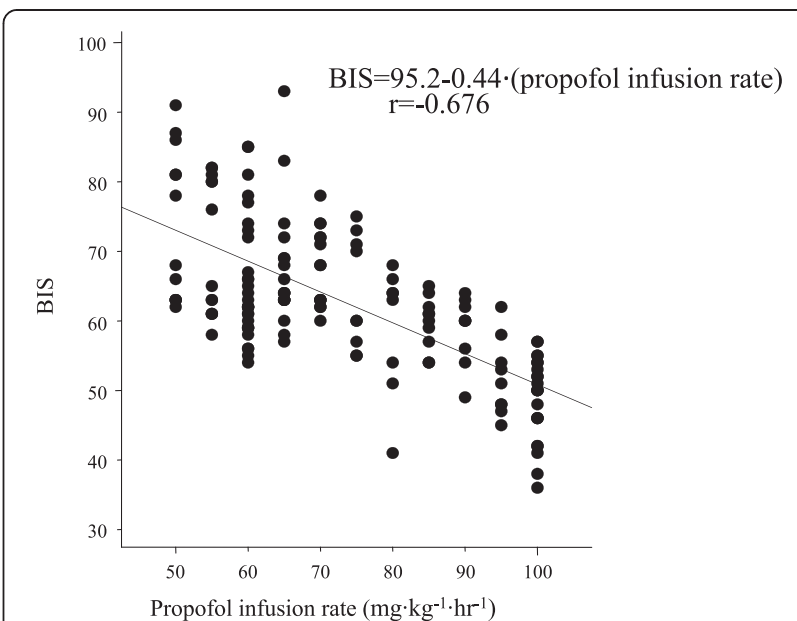

Figure 3 Linear regression between bispectral index and propofol infusion rate in rabbits anesthetized with propofol: BIS $=95-0.44 \cdot\left[\right.$ Propofol $\left.\left(\mathrm{mg} \cdot \mathrm{kg}^{-1} \cdot \mathrm{hr}^{-1}\right)\right], \mathrm{r}=-0.676$.

analgesia, and hemodynamic control. Various brain function monitors have thus been developed in an effort to provide a more global measure of anesthetic (or at least hypnotic) effect. Spectral edge frequency 95 (SEF95) was the first generally accepted electroencephalographic measure [16], but the BIS is now by far the most commonly used measure of hypnotic effect [17]. And unlike many other measures, it appears to be generally reliable across a variety of anesthetic drug classes and combinations of anesthetic drugs including analgesics including propofol, isoflurane, thiopental, or midazolam, supplemented with various amounts for opioids and nitrous oxide [18].

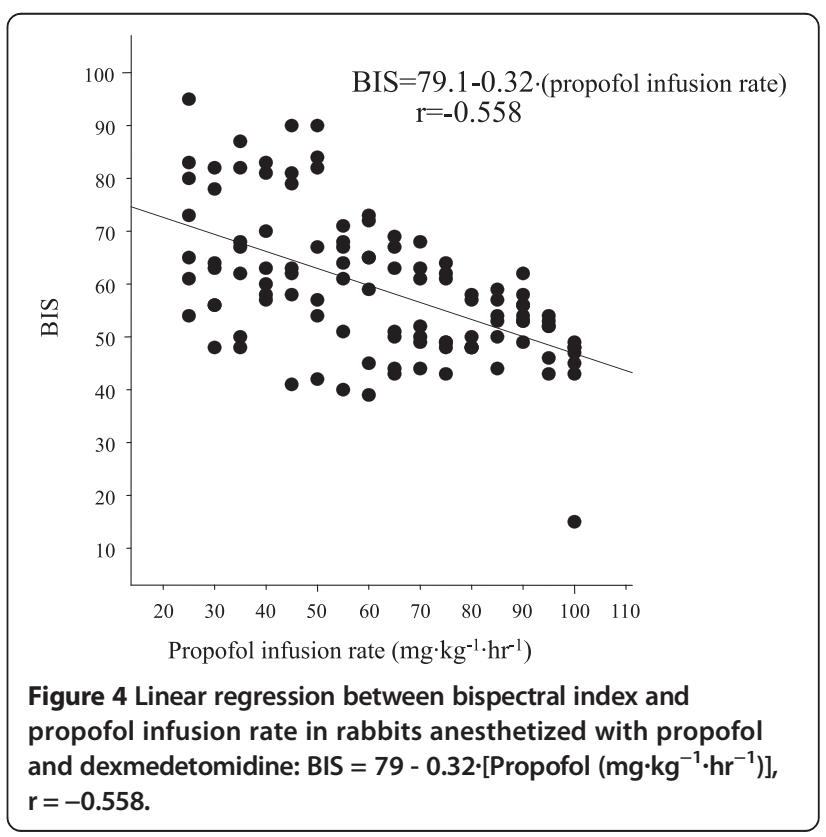


In the previous human studies, BIS values were linearly correlated with effect-site sevoflurane concentration [19], and propofol blood concentration [20]. We found that BIS values in rabbits were also linearly related to end-tidal sevoflurane concentration and the propofol dose. The correlation line slopes of sevoflurane and propofol were similar to those observed in previous human studies $[19,20]$. Comparable slopes suggest that BIS values are a reasonable gauge of sedation depth in rabbits anesthetized with sevoflurane or propofol.

The MAC of sevoflurane in rabbits is between 3.7 and $4.1 \%$ [21,22]. Interestingly, the end-tidal sevoflurane concentrations that produced BIS $=50$ was almost identical at $3.9 \%$. This result is consistent with the general finding that volatile anesthetic potency is comparable across a wide variety of species.

The hypnotic dose of propofol in rabbits remains controversial. Luo et al [23] used 24-48 $\mathrm{mg} \cdot \mathrm{kg}^{-1} \cdot \mathrm{hr}^{-1}$ of propofol with ketamine and fentanyl. Baumgartner et al [24] used 90-102 mg. $\mathrm{kg}^{-1} \cdot \mathrm{hr}^{-1}$ of propofol with fentanyl or dipyrone. Martín-Cancho et al [3] reported that propofol dose of $36 \mathrm{mg} \cdot \mathrm{kg}^{-1} \cdot \mathrm{hr}^{-1}$ was associated with BIS values of 69.1. From our results, dose of propofol that makes BIS at 70 is calculated to be $57.3 \mathrm{mg} \cdot \mathrm{kg}^{-1} \cdot \mathrm{hr}^{-1}$ (Figure 3). This dose is 1.6 times higher than that in the previous study, however, the dose is not extremely high. Our results may concur with the previous study. Results of previous studies suggest that the necessary infusion rate for propofol in rabbits varies from 24 to $100 \mathrm{mg} \cdot \mathrm{kg}^{-1} \cdot \mathrm{hr}^{-1}$ $[23,24]$. We found that infusion rate of propofol that adjusted BIS value at 50 was $101 \mathrm{mg} \cdot \mathrm{kg}^{-1} \cdot \mathrm{hr}^{-1}$, suggesting that the higher published doses may be most suitable. We note, though, that dose must be interpreted in the context of ancillary medications which themselves contribute to anesthetic effect and thus influence BIS values. In patients, a more typical dose would be $5.3 \mathrm{mg} \cdot \mathrm{kg}^{-1} \cdot \mathrm{hr}^{-1}$ [25]. Rabbits thus require more propofol than humans.

Dexmedetomidine decreases both the MAC of sevoflurane and propofol requirements in humans [26,27]. For example, dexmedetomidine decreases BIS in swine given a constant infusion of propofol [28]. Dexmedetomidine similarly decreases the MAC of sevoflurane by about $50 \%$ in ponies [29]. Our results in rabbits are generally consistent, with dexmedetomidine reducing sevoflurane requirement by $33 \%$ and propofol requirement by $14 \%$.

Continuous infusion rate of dexmedetomidine at 0.25 $1 \mu \mathrm{g} \cdot \mathrm{kg}^{-1} \cdot \mathrm{hr}^{-1}$ is recommended for humans. Kilic et al [30] reported that the dose of dexmedetomidine was $10 \mu \mathrm{g} \cdot \mathrm{kg}^{-1}$ followed by a maintenance dose of $10 \mu \mathrm{g} \cdot \mathrm{kg}^{-1} \cdot \mathrm{hr}^{-1}$. Chang et al [31] reported that infusion dose of dexmedetomidine was at $2 \mu \mathrm{g} \cdot \mathrm{kg}^{-1} \cdot \mathrm{hr}^{-1}$. Rabbits may need large amount of dexmedetomidine compared with human. Used dose of dexmedetomidine at $3.5 \mu \mathrm{g} \cdot \mathrm{kg}^{-1} \cdot \mathrm{hr}^{-1}$ in this study could be adaptable for rabbits.
Blood pressure and heart rate were essentially unchanged by sevoflurane and propofol alone. Even at $100 \mathrm{mg} \cdot \mathrm{kg}^{-1}$ of propofol did not induce hypotension. In contrast, dexmedetomidine decreased blood pressure and heart rate just as would be expected from a central alpha- 2 receptor agonist that also acts on pre-synaptic alpha-2 adrenergic receptor and suppresses norepinephrine release [32,33]. The employed dose of dexmedetomidine at $3.5 \mu \mathrm{g} \cdot \mathrm{kg}^{-1} \cdot \mathrm{hr}^{-1}$ could be the origin of decrease in blood pressure. However, although propofol $100 \mathrm{mg} \cdot \mathrm{kg}^{-1} \cdot \mathrm{hr}^{-1}$ combined with dexmedetomidine 3.5 $\mathrm{mcg} \cdot \mathrm{kg}^{-1} \cdot \mathrm{hr}^{-1}$ decreased blood pressure, that combination did not induce severe hypotension. In contrast to our steady-state measurements, initiating dexmedetomidine - or rapid dose increases - can increase blood pressure in response to unopposed stimulation of peripheral alpha- 2 receptors. However, the increase is usually transient and of minimal clinical consequence [34].

In animal studies, airway management is crucial. Su et al [35] reported that tracheal intubation in rabbits was difficult because of their features such as limited mandibular range, a large tongue and prominent incisors. We also experienced that tracheal intubation in rabbits was very difficult. Tracheotomy is commonly used method for airway management for rabbit studies, and it is a reliable method for protecting the airway. Therefore, we employed tracheotomy.

A limitation of our study is that it depends critically on BIS being valid in rabbits, and a BIS value of 50 representing optimal anesthetic depth. Although not extensively validited, BIS appears to work well in animals $[4,5]$ including rabbits [3]. We also assumed that BIS values have comparable meanings with sevoflurane, propofol, and dexmedetomodine. BIS is not a "universal tool". For example, nitrous oxide [36] and ketamine [37] have little effects on BIS, although they are perfectly good anesthetics. However, nitrous oxide and ketamine appear to be exceptions, with most other anesthetics having roughly comparable effects on BIS.

The rabbits in our study had a tracheostomy, but did not experience the kind of pain that results from major surgery. During major surgery, either sevoflurane or propofol would need to be accompanied by an analgesic, usually an opioid [38,39]. And finally, we report propofol dose rather than plasma concentration. Concentration would provide a better pharmacokinetic estimate, and in humans effect-site concentration would be calculated from established models. But such models do not exist for rabbits, and dose is more clinically useful than blood concentration which cannot be measured in real time.

\section{Conclusions}

The sevoflurane concentration at BIS $=50$ was $3.9 \%$ in the sevoflurane group and $2.6 \%$ in the sevoflurane + 
dexmedetomidine group. The propofol infusion rate to make BIS = 50 was $101 \mathrm{mg} \cdot \mathrm{kg}^{-1} \cdot \mathrm{hr}^{-1}$ in the propofol group, and $90 \mathrm{mg} \cdot \mathrm{kg}^{-1} \cdot \mathrm{hr}^{-1}$ in the propofol + dexmedetomidine group. The optimal end-tidal concentration of sevoflurane alone was thus $3.9 \%$, and optimal infusion rate for propofol alone was $101 \mathrm{mg} \cdot \mathrm{kg}^{-1} \cdot \mathrm{hr}^{-1}$. Dexmedetomidine reduced sevoflurane requirement by $33 \%$ and propofol requirement by $11 \%$.

\section{Abbreviations}

BIS: Bispectral index; Cl: Confidence intervals; MAC: Minimum Alveolar Concentration; SEF95: Spectral edge frequency 95.

\section{Competing interests}

This study is supported in part by Grants-in-Aid for Research No. C-23592246 from the Japan Society for the Promotion of Science, Tokyo, Japan.

\section{Authors' contributions}

YT: I conducted the study, acquired the data, and wrote the draft of manuscript. TI: I designed the study, analyzed and interpreted the data, wrote the manuscript, and the corresponding author. NA: I helped conduct the study, acquired the data, and approved the final manuscript. MK: I helped conduct the study, acquired the data, and approved the final manuscript. KI: I helped designed the study, analyzed and interpreted the data, and approved the final manuscript. NS: I reviewed the analysis and interpretation of the data and approved the final manuscript. DIS: I revised the manuscript and approved the final version. TM: I revised the manuscript and approved the final version. All authors read and approved the final manuscript.

\section{Authors' information}

Yoshihide Terada: Instructor, Department of Anesthesiology, Faculty of Medicine, University of Yamanashi.

Tadahiko Ishiyama: Associate Professor and Chair, Surgical Center, University of Yamanashi Hospital.

Nobumasa Asano: Instructor, Department of Anesthesiology, Faculty of Medicine, University of Yamanashi.

Masakazu Kotoda: Instructor, Surgical Center, University of Yamanashi Hospital.

Kodai Ikemoto: Instructor, Department of Anesthesiology, Faculty of Medicine, University of Yamanashi.

Noriyuki Shintani: Instructor, Department of Anesthesiology, Faculty of Medicine, University of Yamanashi.

Daniel I Sessler; Michael Cudahy Professor and Chair, Department of Outcomes Research, The Cleveland Clinic.

Takashi Matsukawa: Professor and Chair, Department of Anesthesiology, Faculty of Medicine, University of Yamanashi.

\section{Author details}

'Department of Anesthesiology, Faculty of Medicine, University of Yamanashi, 1110 Shimokato, Chuo, Yamanashi 409-3898, Japan. ${ }^{2}$ Surgical Center, University of Yamanashi Hospital, University of Yamanashi, 1110 Shimokato, Chuo, Yamanashi 409-3898, Japan. ${ }^{3}$ Department of Outcomes Research, The Cleveland Clinic, Cleveland, Ohio, USA.

Received: 7 March 2014 Accepted: 6 November 2014

Published: 19 November 2014

\section{References}

1. Ishiyama T, Shibuya K, Ichikawa M, Masamune T, Kiuchi R, Sessler DI, Matsukawa T: Cerebral pial vascular changes under propofol or sevoflurane anesthesia during global cerebral ischemia and reperfusion in rabbits. J Neurosurg Anesthesiol 2010, 22:207-213.

2. Gerlach AT, Murphy CV, Dasta JF: An updated focused review of dexmedetomidine in adults. Ann Pharmacother 2009, 43:2064-2074.

3. Martín-Cancho MF, Lima JR, Luis L, Crisóstomo V, Carrasco-Jiménez MS, Usón-Gargallo J: Relationship of bispectral index values, haemodynamic changes and recovery times during sevoflurane or propofol anaesthesia in rabbits. Lab Anim 2006, 40:28-42.
4. Bleijenberg EH, Van Oostrom H, Akkerdaas LC, Doornenbal A, Hellebrekers $\mathrm{LJ}$ : Bispectral index and the clinically evaluated anaesthetic depth in dogs. Vet Anaesth Analg 2011, 38:536-543.

5. Shibuya K, Ishiyama T, Ichikawa M, Sato H, Okuyama K, Sessler DI, Matsukawa T: The direct effects of propofol on pial microvessels in rabbits. J Neurosurg Anesthesiol 2009, 21:40-46.

6. Whyte SD, Booker PD: Monitoring depth of anaesthesia by EEG. Contin Educ Anaesth Crit Care Pain 2003, 3:106-110.

7. Liu J, Hu ZY, Ye QQ, Dai SH: Development of three Drosophila melanogaster strains with different sensitivity to volatile anesthetics. Chin Med J 2009, 122:561-565.

8. Shim CY, Andersen NB: The effect of oxygen on minimal anesthetic requirements in the toad. Anesthesiology 1971, 34:333-337.

9. Waizer PR, Baez S, Orkin LR: A method for determining minimum alveolar concentration of anesthetic in the rat. Anesthesiology 1973, 39:394-397.

10. St A, Stewart L, Martin WJ: Evaluation of postoperative analgesia in a rat model of incisional pain. Contemp Top Lab Anim Sci 2003, 42:28-34.

11. Eikermann M, Grosse-Sundrup M, Zaremba S, Henry ME, Bittner EA, Hoffmann U, Chamberlin NL: Ketamine activates breathing and abolishes the coupling between loss of consciousness and upper airway dilator muscle dysfunction. Anesthesiology 2012, 116:35-46.

12. Fahey MR, Sessler DI, Cannon JE, Brady K, Stoen R, Miller RD: Atracurium, vecuronium, and pancuronium do not alter the minimum alveolar concentration of halothane in humans. Anesthesiology 1989, 71:53-56.

13. Liem EB, Lin CM, Suleman MI, Gregg RG, Veauthier JM, Loyd G, Sessler DI: Anesthetic requirement is increased in redheads. Anesthesiology 2004, 101:279-283.

14. Ezri T, Sessler D, Weisenberg M, Muzikant G, Protianov M, Mascha E, Evron S: Association of ethnicity with the minimum alveolar concentration of sevoflurane. Anesthesiology 2007, 107:9-14.

15. Leslie K, Sessler DI, Smith WD, Larson MD, Ozaki M, Blanchard D, Crankshaw DP: Prediction of movement during propofol/nitrous oxide anesthesia. Performance of concentration, electroencephalographic, pupillary, and hemodynamic indicators. Anesthesiology 1996, 84:52-63.

16. Homer TD, Stanski DR: The effect of increasing age on thiopental disposition and anesthetic requirement. Anesthesiology 1985, 62:714-724.

17. Rampil IJ: A primer for EEG signal processing in anesthesia. Anesthesiology 1998, 89:980-1002.

18. Glass PS, Bloom M, Kearse L, Rosow C, Sebel P, Manberg P: Bispectral analysis measures sedation and memory effects of propofol, midazolam, isoflurane, and alfentanil in healthy volunteers. Anesthesiology 1997, 86:836-847.

19. Olofsen $E$, Dahan $A$ : The dynamic relationship between end-tidal sevoflurane and isoflurane concentrations and bispectral index and spectral edge frequency of the electroencephalogram. Anesthesiology 1999, 90:1345-1353.

20. Leslie K, Sessler DI, Schroeder M, Walters K: Propofol blood concentration and the Bispectral Index predict suppression of learning during propofol/epidural anesthesia in volunteers. Anesth Analg 1995, 81:1269-1274

21. Scheller MS, Saidman LJ, Partridge BL: MAC of sevoflurane in humans and the New Zealand white rabbit. Can J Anaesth 1988, 35:153-156.

22. Yin $Y$, Yan M, Zhu T: Minimum alveolar concentration of sevoflurane in rabbits with liver fibrosis. Anesth Analg 2012, 114:561-565.

23. Luo Y, Russell GB, Griffith JW, Lang CM: Comparison of anesthesia induced by ketamine-fentanyl combination and maintained by propofol or etomidate in New Zealand white rabbits. Lab Anim Sci 1995, 45:269-275.

24. Baumgartner C, Koenighaus H, Ebner J, Henke J, Schuster T, Erhardt W: Comparison of dipyrone/propofol versus fentanyl/propofol anaesthesia during surgery in rabbits. Lab Anim 2011, 45:38-44.

25. Reboso JA, Méndez JA, Reboso HJ, León AM: Design and implementation of a closed-loop control system for infusion of propofol guided by bispectral index (BIS). Acta Anaesthesiol Scand 2012, 56:1032-1041.

26. Fragen RJ, Fitzgerald PC: Effect of dexmedetomidine on the minimum alveolar concentration (MAC) of sevoflurane in adults age 55 to 70 years. J Clin Anesth 1999, 11:466-470.

27. Wang T, Ge S, Xiong W, Zhou P, Cang J, Xue Z: Effects of different loading doses of dexmedetomidine on bispectral index under stepwise propofol target-controlled infusion. Pharmacology 2013, 91:1-6.

28. Sano H, Doi M, Mimuro S, Yu S, Kurita T, Sato S: Evaluation of the hypnotic and hemodynamic effects of dexmedetomidine on propofol-sedated swine. Exp Anim 2010, 59:199-205. 
29. Gozalo-Marcilla M, Hopster K, Gasthuys F, Hatz L, Krajewski AE, Schauvliege S: Effects of a constant-rate infusion of dexmedetomidine on the minimal alveolar concentration of sevoflurane in ponies. Equine Vet J 2013, 45:204-208.

30. Kilic K, Hanci V, Selek S, Sozmen M, Kilic N, Citil M, Yurtlu DA, Yurtlu BS: The effects of dexmedetomidine on mesenteric arterial occlusion-associated gut ischemia and reperfusion-induced gut and kidney injury in rabbits. J Surg Res 2012, 178:223-232.

31. Chang C, Uchiyama A, Ma L, Mashimo T, Fujino Y: A comparison of the effects on respiratory carbon dioxide response, arterial blood pressure, and heart rate of dexmedetomidine, propofol, and midazolam in sevoflurane-anesthetized rabbits. Anesth Analg 2009, 109:84-89.

32. Seyrek M, Halici Z, Yildiz O, Ulusoy HB: Interaction between dexmedetomidine and -adrenergic receptors: emphasis on vascular actions. J Cardiothorac Vasc Anesth 2011, 25:856-862.

33. Kallio A, Scheinin M, Koulu M, Ponkilainen R, Ruskoaho H, Viinamaki O, Scheinin $\mathrm{H}$ : Effects of dexmedetomidine, a selective alpha 2-adrenoceptor agonist, on hemodynamic control mechanisms. Clin Pharmacol Ther 1989, 46:33-42.

34. Bloor BC, Ward DS, Belleville JP, Maze M: Effects of intravenous dexmedetomidine in humans. II. Hemodynamic changes. Anesthesiology 1992, 77:1134-1142.

35. Su HP, Hou CJ, Chen WH, Wang KJ, Chiu YH, Sun HS: A miniature lighted stylet for fast oral endotracheal intubation in rabbits. Vet J 2013, 195:254-256.

36. Rampil IJ, Kim JS, Lenhardt R, Negishi C, Sessler DI: Bispectral EEG index during nitrous oxide administration. Anesthesiology 1998, 89:671-677.

37. Hans P, Dewandre PY, Brichant JF, Bonhomme V: Comparative effects of ketamine on bispectral index and spectral entropy of the electroencephalogram under sevoflurane anaesthesia. $\mathrm{Br} J$ Anaesth 2005, 94:336-340.

38. Onuki $\mathrm{K}$, Onuki N, Imamura T, Yamanishi $Y$, Yoshikawa S, Hagihira S, Shimada J, Nagasaka H: Pentazocine increases bispectral index without surgical stimulation during nitrous oxide-sevoflurane anesthesia. J Anesth 2011, 25:946-949.

39. Strachan AN, Edwards ND: Randomized placebo-controlled trial to assess the effect of remifentanil and propofol on bispectral index and sedation. Br J Anaesth 2000, 84:489-490.

doi:10.1186/1756-0500-7-820

Cite this article as: Terada et al: Optimal doses of sevoflurane and propofol in rabbits. BMC Research Notes 2014 7:820.

\section{Submit your next manuscript to BioMed Central and take full advantage of:}

- Convenient online submission

- Thorough peer review

- No space constraints or color figure charges

- Immediate publication on acceptance

- Inclusion in PubMed, CAS, Scopus and Google Scholar

- Research which is freely available for redistribution

Submit your manuscript at www.biomedcentral.com/submit
(O) Biomed Central 